\title{
Switching from seismic to seismo-acoustic harmonic tremor at a transition of eruptive activity during the Shinmoe-dake 2011 eruption
}

\author{
Mie Ichihara ${ }^{1}$, John J. Lyons ${ }^{2}$, and Akihiko Yokoo ${ }^{3}$ \\ ${ }^{1}$ Earthquake Research Institute, University of Tokyo, 1-1-1 Yayoi, Bunkyo-ku, Tokyo 113-0032, Japan \\ ${ }^{2}$ Alaska Volcano Observatory, U.S. Geological Survey, Anchorage, AK, U.S.A. \\ ${ }^{3}$ Aso Volcanological Laboratory, Institute for Geothermal Sciences, Kyoto University, Minami-Aso, Kumamoto 869-1404, Japan
}

(Received October 31, 2012; Revised April 9, 2013; Accepted May 3, 2013; Online published July 8, 2013)

\begin{abstract}
This paper reports a sequence of harmonic tremor observed during the 2011 eruption of Shinmoe-dake volcano, Kyushu, Japan. The main eruptive activity started with subplinian eruptions, followed by lava effusion. Harmonic tremor was observed as seismic waves during the final stage of the effusive eruption. The tremor observed at this stage had unclear and fluctuating harmonic modes. In the atmosphere, however, many impulsive acoustic waves indicating small surface explosions were observed. When effusion stopped and explosive degassing began, harmonic tremor was observed as acoustic waves in the air and in the seismic data, and the harmonic modes became clearer and more stable. This transition in the character of the harmonic tremor coincided with rapid deflation of the lava that had accumulated in the crater. Based on these observations, and laboratory experiments reproducing the features of the wave fields, it is concluded that the harmonic tremor sequence at Shinmoe-dake was generated by gas flowing through channels in the gradually solidifying lava. Comparing our results with the few cases of similar transition observed at other volcanoes, we expect that the transition indicates changes in magma rheology and degassing conditions in the crater, and therefore of changes in eruptive activity.
\end{abstract}

Key words: Harmonic tremor, infrasound, lava deflation, degassing, lava viscosity, bubbles.

\section{Introduction}

Active volcanoes generate a variety of oscillations in the ground and in the air. Among them is what is called 'harmonic tremor (HT)'. As the name indicates, HT is a sustained oscillation consisting of a fundamental mode and its overtones. The regularly repeating wavefield suggests some non-linear feedback mechanism, and volcanoes are often compared to flow-driven musical instruments (Julian, 1994; Lesage et al., 2006; Rust et al., 2008), in which either magma or gas may be 'blowing' the instrument. Although the unique features of HT oscillations have attracted researchers for decades, sources have not been exclusively determined for any observed cases.

Previous studies of HT have primarily focused on seismic observations. However, observations of volcanicallygenerated infrasound are increasing, and HT has also been found in the atmosphere (Hagerty et al., 2000; Lees et al., 2008). Within the same period of activity, HT is sometimes transmitted both in the air and in the ground (SAHT: Seismo-Acoustic HT), but other times transmitted only in the ground (SHT: Seismic HT) (Lees et al., 2008). The accompanying paper (Lyons et al., 2013) presents a laboratory experiment simulating the feature of switching between SHT and SAHT and applies the model to observations at Fuego volcano, Guatemala. Here, we add a new

Copyright (c) The Society of Geomagnetism and Earth, Planetary and Space Sciences (SGEPSS); The Seismological Society of Japan; The Volcanological Society of Japan; The Geodetic Society of Japan; The Japanese Society for Planetary Sciences; TERRAPUB.

doi:10.5047/eps.2013.05.003 observation of SHT-SAHT switching that occurred in the 2011 eruption of Shinmoe-dake in Kyushu, Japan. In this case, the conditions and timing of eruptive activity when the switching occurred were well constrained for the first time.

Shinmoe-dake is an andesitic stratovolcano that belongs to the Kirishima volcano complex, south of Kyushu, Japan (Fig. 1). A major magmatic eruption occurred there in 2011 after 300 years of quiescence (Imura and Kobayashi, 1991; Tsutsui et al., 2005). Crustal deformation associated with the eruption was observed with GPS and tiltmeters, and the data are interpreted as the volumetric decrease of a magma chamber located about $7 \mathrm{~km}$ to the northwest of the crater (the star in Fig. 1) at a depth of 8-10 km below sea level (Kozono et al., 2013; Nakao et al., 2013; Ueda et al., 2013). The main eruptive activity started with 3 subplinian eruptions on the 26th and 27th of January 2011, and was followed by emplacement of lava in the crater from the 28th to the 31 st. The lava emplaced in the crater was too flat to be defined as a lava dome, but was too solid to be called a lava lake. It was more similar to a so-called pancake dome (Fink and Griffiths, 1998). The eruptive activity turned to intermittent strong vulcanian explosions on the 1st of February. A few tens of vulcanian explosions occurred from February $1-7$, after which the volcanic activity gradually declined over the following year. HT events were observed in the last stage of the lava emplacement and during the subsequent vulcanian stage. In this paper, we characterize the switching from SHT to SAHT in the sequence of the eruption activity, and discuss the applicability of the laboratory 

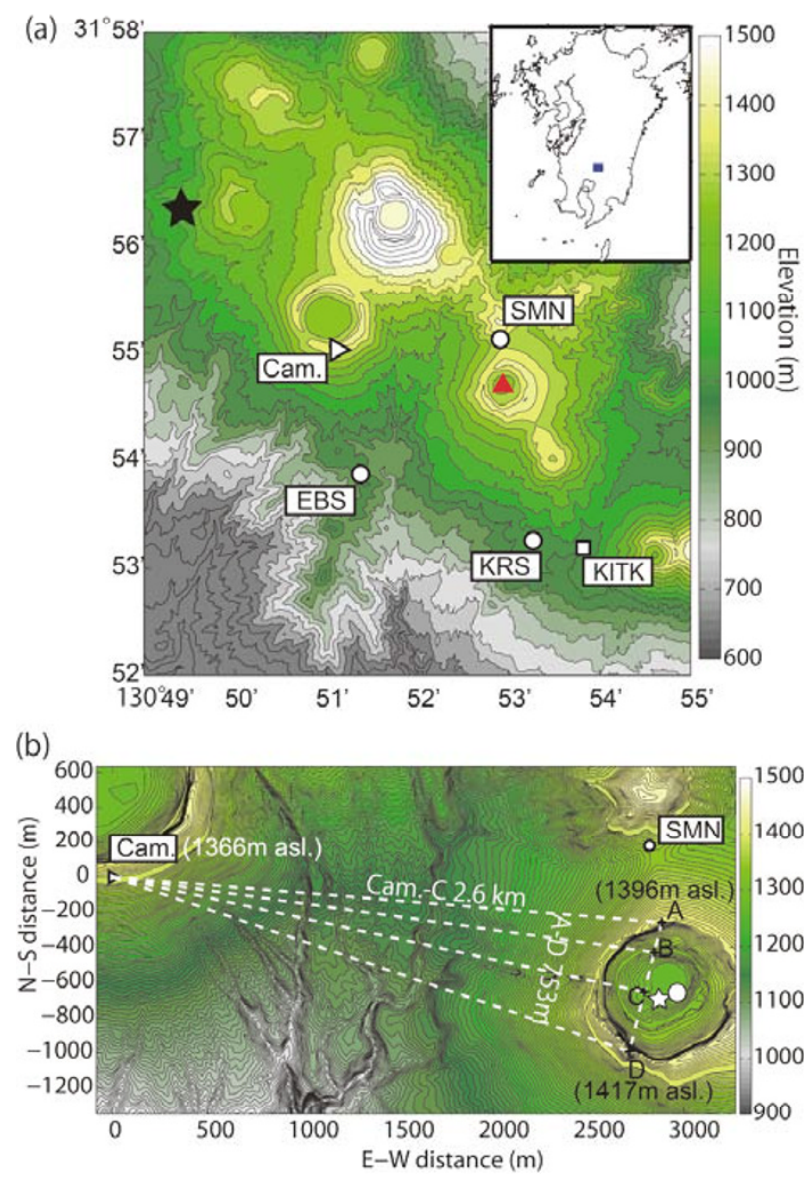

Fig. 1. (a) Seismic and acoustic stations (SMN, KRS, EBS), a tiltmeter station (KITK), and a monitoring camera (Cam.), nearby Shinmoe-dake crater (the red triangle). The geodetic source volume of the 2011 Shinmoe-dake eruption is $8-10 \mathrm{~km}$ beneath the solid star. (b) A zoomed-in map of (a). From Cam. to A-D are the directions of topographic landmarks used as the scale references in the image analyses. The Cam.-C line follows a chain of craters generated by the previous eruption on the flank of Shinmoe-dake. The open star and circle indicate the locations of the source of lava effusion and the degassing vent at the surface of the lava, respectively (Nakada et al., 2013).

model by Lyons et al. (2013). The observations reported in this paper provide an excellent opportunity to investigate the mechanism of SHT-SAHT switching and to broaden our knowledge of HT phenomena in general.

\section{Observation at Shinmoe-Dake}

\subsection{Stations and instruments}

Locations of the stations used in this work are summarized in Fig. 1.

The Earthquake Research Institute of the University of Tokyo operates several permanent telemetered broadband seismic stations (Trillium 120P) near the volcano. An infrasonic microphone (Hakusan, SI102, 0.1-1000 Hz) was installed on the 6th of December 2010 to SMN, the station nearest to Shinmoe-dake crater. The same type of infrasound microphones were added to other stations, KRS and EBS, on the 29th and 30th of January 2011, respectively, after the eruption started. All the stations were recorded continuously with a sample rate of $100 \mathrm{~Hz}$.

A permanent light-sensitive monitoring camera is op-

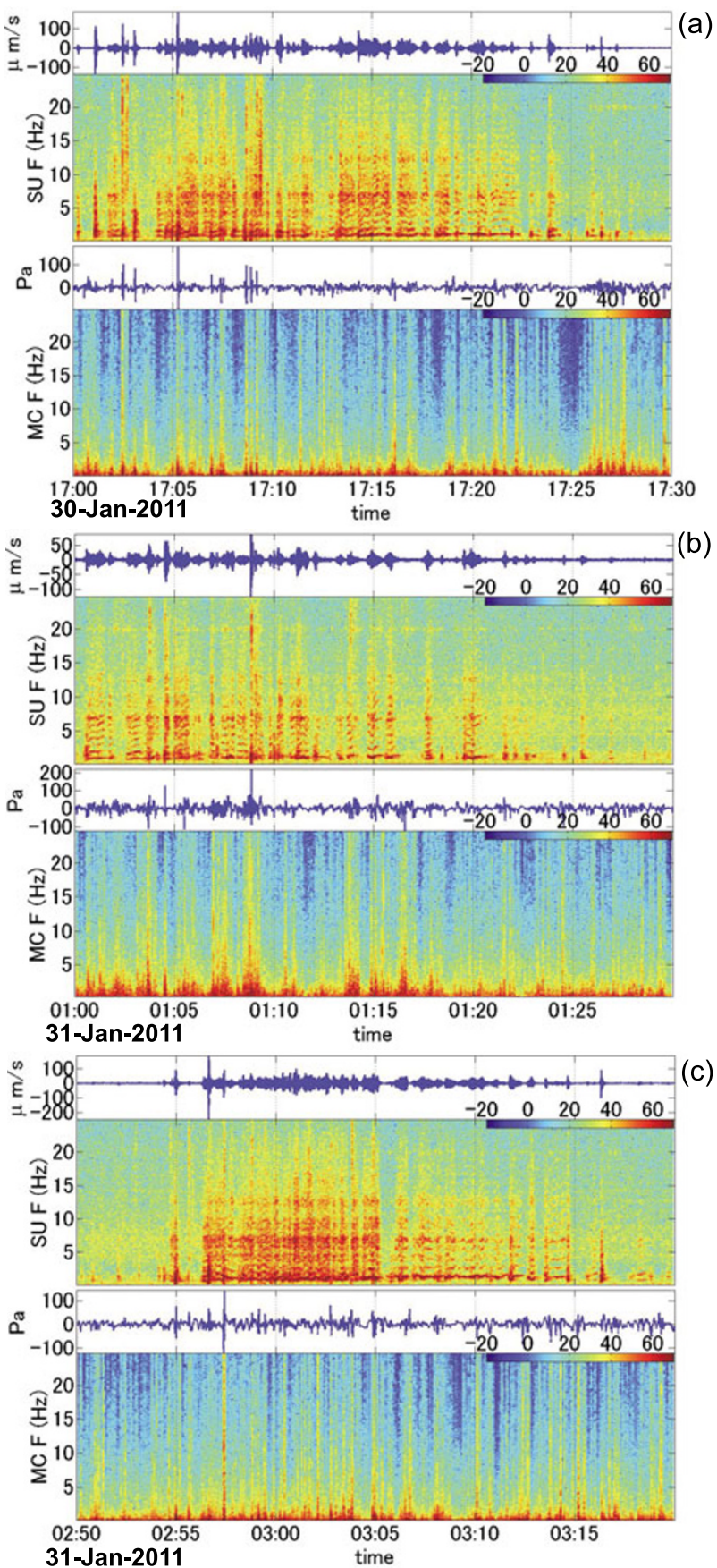

Fig. 2. Three examples of seismic harmonic tremor (SHT) observed at SMN. The acoustic signal is impulsive and shows no HT. In each case, the upper framed is the waveform and spectrogram of the vertical ground velocity and the lower frames are those of the acoustic signal. The first recognized SHT event is shown in (a).

erated by Aira-Isa Regional Development Bureau of Kagoshima prefecture about $3 \mathrm{~km}$ west of Shinmoe-dake. The elevation of the camera location is $1366 \mathrm{~m}$, which is slightly higher than the west side of the crater rim of Shinmoe-dake $(1350-1360 \mathrm{~m})$. The image $(640 \times 480$ pixels, $30 \mathrm{fps}$ ) was transferred to the bureau in real time and saved every 2 seconds during the eruption. The angle and zoom of the camera were not fixed but remotely controlled for monitoring purposes. The scale of an image was calculated using the positions of the topographic features 


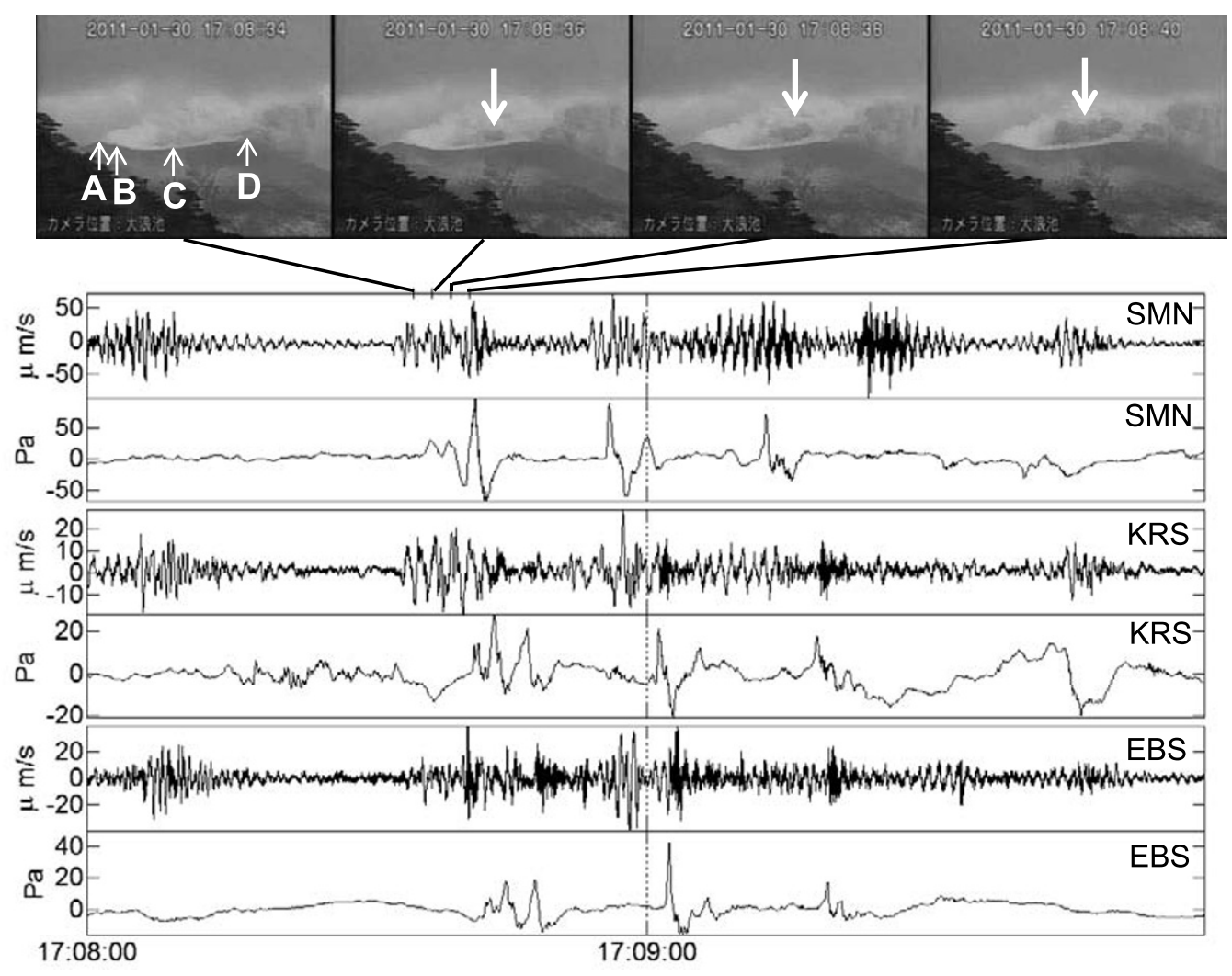

30-Jan-2011

Fig. 3. A close-up view of the seismic (the vertical component) and the acoustic waves measured at the three stations for the case of Fig. 2(a). A-D in the image indicate the reference points (Fig. 2(b)) for the scale with A-D being $753 \mathrm{~m}$. The acoustic pulses are associated with small surface explosions (down arrows). The red lines indicate the times of the images taken by the monitoring camera.

(Fig. 1(b)). The distance between the peaks on the north and south sides of the crater rim is $753 \mathrm{~m}$, and their elevations are $1396 \mathrm{~m}$ and $1419 \mathrm{~m}$, respectively.

\subsection{Switching from SHT to SAHT}

The first SHT was recognized around 17:00 on January 30 and then intermittently observed until the middle of the 31 st. The SHT at this stage had unclear and fluctuating harmonic modes, but the fundamental frequency was most often at $0.9,1.05$, and $1.3 \mathrm{~Hz}$. On the other hand, the microphone data showed many impulsive signals associated with explosions but without HT (Fig. 2; Fig. 3). The impulsive acoustic waves are associated with small explosions (Fig. 3). It is noted that the absence of harmonic modes in the microphone spectrogram (Fig. 2) was not because they were obscured by the strong impulsive acoustic waves. Even in the time windows without impulsive waves (e.g., Fig. 3, 30 seconds from 17:08), the harmonic modes were observed only in the seismic records.

The first SAHT appeared at 21:49 on January 31. In total, 6 SAHT events were subsequently recognized until February 6. Each event had a different eruption feature at the onset. The first started 1 minute after a small explosion, but it grew gradually in intensity (Fig. 4(a)). No surface explosions were observed during the SAHT. The second appeared 14 minutes after a very strong explosion at 7:54 on February 1. The acoustic signal started as a couple of successive small impulses associated with explosions, which then seemed to shift to regular oscillation coupled with seis- mic HT (Fig. 5). The third is the longest event, which continued with several intervals from 20:40 to 21:30 on the 2nd of February (Fig. 4(b)). No explosions or impulsive acoustic signals were recognized during this period. A clear, but short, SAHT occurred at 6:08 on the 3rd. The last two events were less clear and very weak (Fig. 4(c)). The fundamental frequency was also variable between the events, ranging between $0.85 \mathrm{~Hz}$ to $2 \mathrm{~Hz}$. The two clear events that occurred on February 2 (Fig. 4(b)) and on February 3 had fundamental frequencies of $0.95-1.1 \mathrm{~Hz}$, which was within the range of those observed in the SHT events. Regardless of these variations, all the SAHT events showed harmonic modes that were clearer and more stable within a sequence of events (Fig. 4) than those of SHT (Fig. 2).

\subsection{Lava emplacement and deformation in the crater}

The formation of the pancake dome was first noticed near the center of the crater floor (the open star in Fig. 1(b), $1271 \mathrm{~m}$ asl.) on the morning of January 28 during a helicopter overflight (Nakada et al., 2013). The lava quickly filled the crater while flight observations were prevented by bad weather. On the 31 st, many research institutes and broadcasting companies made flights over the crater and filmed the lava in the crater (Fig. 6(a)). It had a concentrically folded surface, at the center of which were vents emitting white plumes (Fig. 6(a), (b)). The location of the vents is projected on the map in Fig. 1(b) (Nakada et al., 2013). The Yomiuri Shimbun broadcasted the aerial photographs of the pancake dome taken at $18: 17$ on the 31 st 


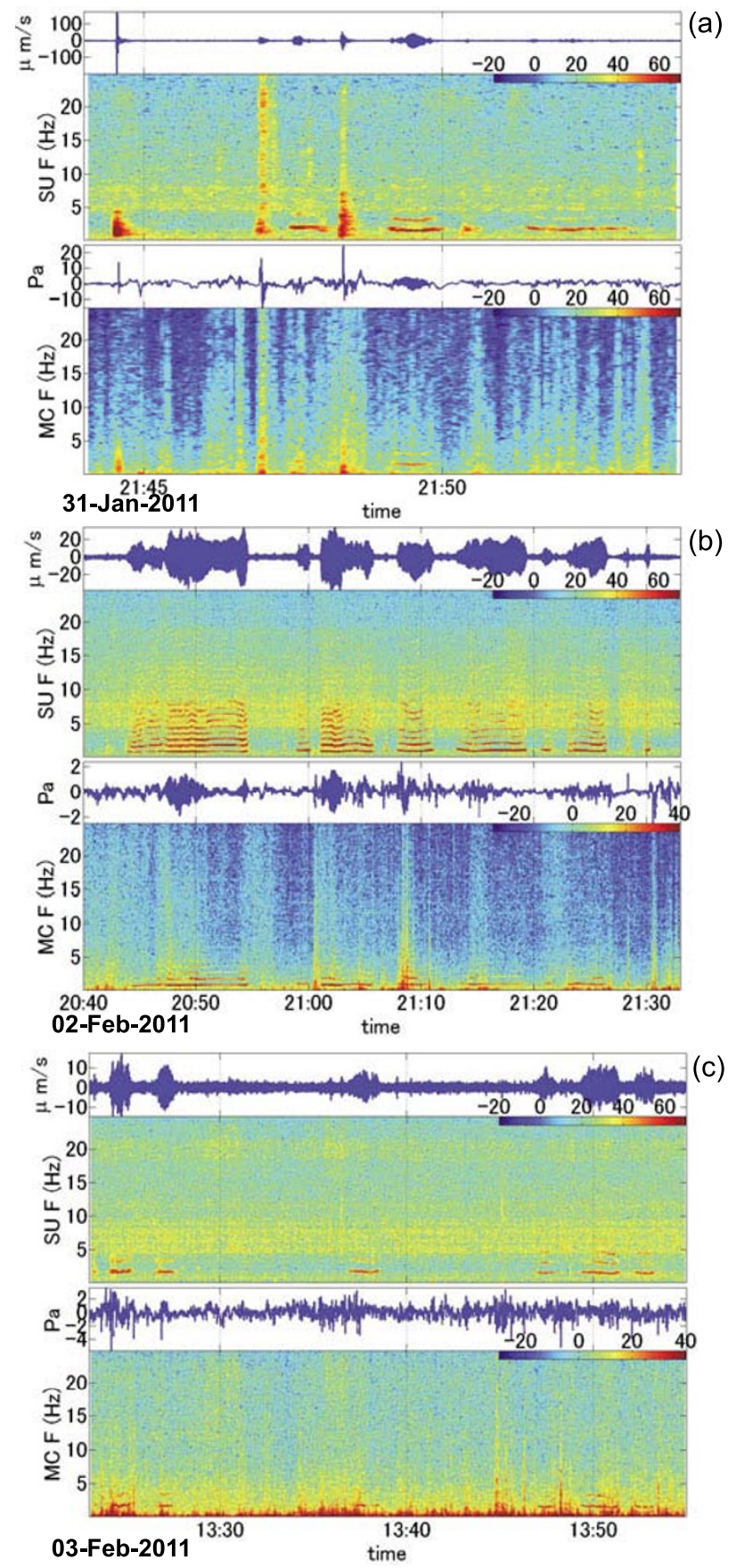

Fig. 4. Three examples of seismo-acoustic harmonic tremor (SAHT) observed at SMN. In each case, the upper frames are the waveform and spectrogram of the vertical ground velocity and the lower frames are those of the acoustic signal. The first recognized SAHT event is shown in (a).

(Fig. 6(b)) and at 9:59 on the next day (Fig. 6(c)). These two pictures show that the pancake dome flattened or shrank between these filming times. The picture taken in the afternoon of the 1st of February more clearly shows the flattened lava surface (Fig. 6(d)).

An aerial photo taken in the evening of January 31 (Fig. 6(b)) shows that the vent glows yellow-red, while other parts of the surface are black. The color of hot lava observed by naked eyes in darkness is yellow-red at the temperature of $700-800^{\circ} \mathrm{C}$, dark red at $600-700^{\circ} \mathrm{C}$, and black below $500-550^{\circ} \mathrm{C}$ (Miyagi and Maejima, 2012). Although colors of digital images are not necessarily the same as those seen by the naked eye, and depend on the camera and its setting, the color distribution of the yellow-red vent (Fig. 6(b)) is similar to the data presented by Miyagi and Maejima (2012) for a basalt surface at $843^{\circ} \mathrm{C}$ photographed by a Nikon D90.

A very strong explosion occurred at 7:54 on February 1 and a petrologic study of dense rock ejected by the explosion showed that the lava consisted of $30 \mathrm{vol} \%$ phenocrysts and melt with $63.9 \mathrm{wt} \%$ of $\mathrm{SiO}_{2}\left(57.9 \mathrm{wt} \% \mathrm{SiO}_{2}\right.$ in the whole rock), and that the magma temperature was 960-980 ${ }^{\circ} \mathrm{C}$ (Suzuki et al., 2013). Using the composition of the melt (Suzuki et al., 2013) and water solubility at the atmospheric pressure (Moore et al., 2008), viscosity of the melt is estimated (Giordano et al., 2008) to be $10^{6} \mathrm{~Pa} \mathrm{~s}$ at $1000^{\circ} \mathrm{C}, 10^{9} \mathrm{~Pa}$ s at $800^{\circ} \mathrm{C}$, and more than $10^{11} \mathrm{~Pa}$ s below $700^{\circ} \mathrm{C}$. The effective viscosity of the lava is larger by a factor due to the effect of phenocrysts (Marsh, 1981; Lejeune and Richet, 1995).

When the pancake dome was growing, the top was barely visible with the monitoring camera over the crater rim (Fig. 7(a)). It was first recognized around 9:00 on January 31 , and was clearly visible during the day. The next morning it could not be seen. The subsidence of the lava surface was analyzed by the following method, because the angle and zoom of the camera were not changed during the night. Reference points were measured using daytime images (Fig. 7(a)), which resulted in a $2.7 \mathrm{~m} /$ pixel scale with $10 \%$ error. This scale was used to measure the height of the lava surface because the vents (Fig. 6(a), (b)) around which the lava was the highest was within $200 \mathrm{~m}$ of the reference line A-D (Fig. 1(b)). Then, for every $2 \mathrm{~s}$ frame, a column with a width of 20 pixels and a height of 150 pixels on the left of reference point $\mathrm{C}$ (Fig. 7(a)) was extracted and averaged over the 20 pixels to obtain a vertical column of $1 \times 150$ pixels. The vertical columns were laterally stacked as shown in Fig. 7(b) for 18:00-19:00 of January 31. This method reveals the silhouette of the lava surface above the crater rim. The surface pixels were picked, and converted to the dome surface elevation (red crosses in Fig. 7(c)) using the scale and the elevation of reference point A (1396 m). For images that show the lava surface relatively clearly, the reference points and the lava surface were individually picked. The results (blue circles in Fig. 7(c)) agree with that of the previously described method.

Processing the camera images reveals that the surface of the lava dome rapidly subsided by $10 \mathrm{~m}$ in an hour $\left(3 \times 10^{-3}\right.$ $\mathrm{m} / \mathrm{s})$ and by $20 \mathrm{~m}$ in less than 6 hours $\left(10^{-3} \mathrm{~m} / \mathrm{s}\right)$ following 18:10. The subsidence corresponds to the apparent strain rate in the order of $10^{-5} \mathrm{~s}^{-1}$, considering the bottom and the top of the dome to be $1271 \mathrm{~m}$ (Fig. 1(b)) and $\sim 1370 \mathrm{~m}$ (Fig. 7(c)), respectively. The first SAHT (Fig. 4(a)) was observed at 21:47. After February 1, the lava surface was sometimes visible when the camera was zoomed but was not clear.

There is a possibility that the surface subsidence shown in Fig. 7(c) was a result of an illusion due to change of the volcanic glow. If a crack had opened on the camera side slope of the lava, the top might be hidden behind the 


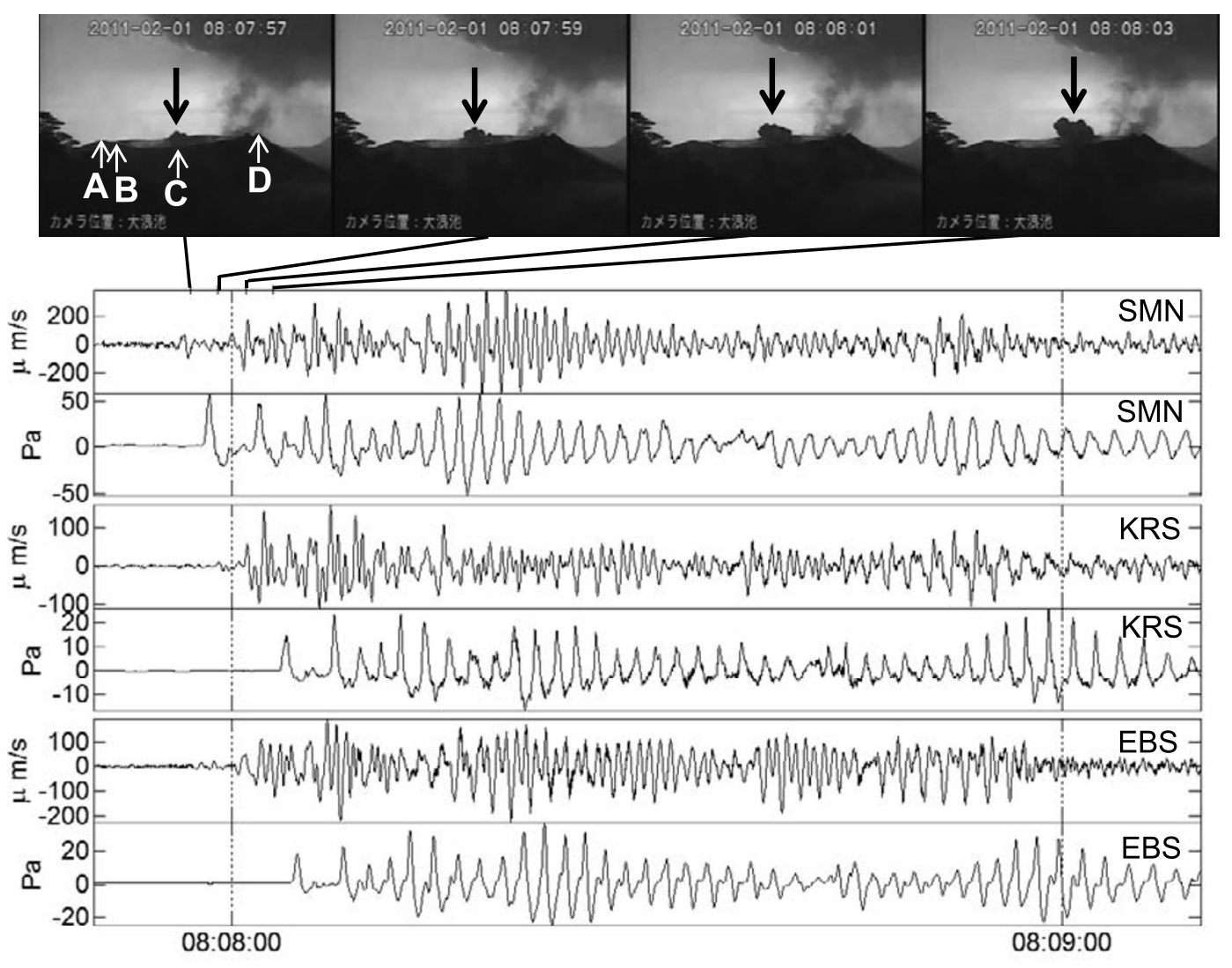

1-Feb-2011

Fig. 5. The beginning of the SAHT event 14 minutes after a big explosion on February 1, 2011 is shown in the same format as Fig. 3. It started with an explosion (down arrows) and then shifted to periodic oscillation.

glows emitted from the crack and apparently seem to be lowered. However, the subsidence had certainly occurred by the morning of February 1, and there is no evidence that the subsidence occurred in different periods during the night.

\subsection{Time histories}

The time histories of the switching from SHT to SAHT and the change of the height of the lava are compared with the other geophysical observations (Fig. 8).

The Japan Meteorology Agency (JMA) operates a tiltmeter (Mitsutoyo, JTS-3B, $5 \mathrm{mV} / \mu \mathrm{rad}$ ) in a 98-m-deep borehole at KITK (Fig. 1(a)). The east-west component of tilt at KITK is shown to illustrate the volume decrease of the magma chamber during the eruptions (Fig. 8(a)). The 3 steps on the 26th and 27th of January correspond to the volume change during the 3 subplinian eruptions, which were estimated to be $1-2 \times 10^{6}$, for the individual steps (Kozono et al., 2013), and the following gradual slope corresponds to the volume change of $5 \times 10^{6} \mathrm{~m}^{3}$ during the lava effusion (Kozono et al., 2013). The volume decrease (figure 5 of Kozono et al., 2013) and the west-down tilt (Fig. 8(a)) halted at 19:00 on the 31st of January.

The RMS amplitudes ( 1 min. time window) of seismic and acoustic signals at $\mathrm{SMN}$ in the $1-7 \mathrm{~Hz}$ frequency range are shown in Fig. 8(b) and 8(c), respectively. Both the seismic and acoustic amplitudes have small but dense spikes from January 29 to 31 during frequent small explosions. Spikes in Fig. 8(b) and 8(c) become stronger with longer intervals after February 1, when vulcanian activity started. The open triangles indicate SHT events, and the solid triangles indicate SAHT events. Figure 8 and photos in Fig. 6 clearly show that the switching from SHT to SAHT, the lava shrinkage, and the transition from frequent small explosions to intermittent vulcanian explosions all occurred on the night of January 31 when magma flow from the chamber stopped.

Based on these observations, we consider that at least the SAHT was generated by gas flow, not by magma flow. Because at Shinmoe-dake SHT and SAHT have common harmonic modes, and they occurred subsequently in the same period of the eruption sequence, we assume an identical gas-driven oscillator for both of SHT and SAHT.

\section{Discussion}

\subsection{A model for SHT-SAHT switching}

The switching from SHT to SAHT at Shinmoe-dake had the following six features.

1) HT started as SHT in the last stage of lava discharge.

2) The harmonic modes were unclear and unstable at this stage.

3) During the SHT events, the acoustic wavefield consisted of impulses associated with small explosions.

4) SAHT started after the lava discharge stopped.

5) The harmonic modes in SAHT are clearer and more stable than those in SHT. 

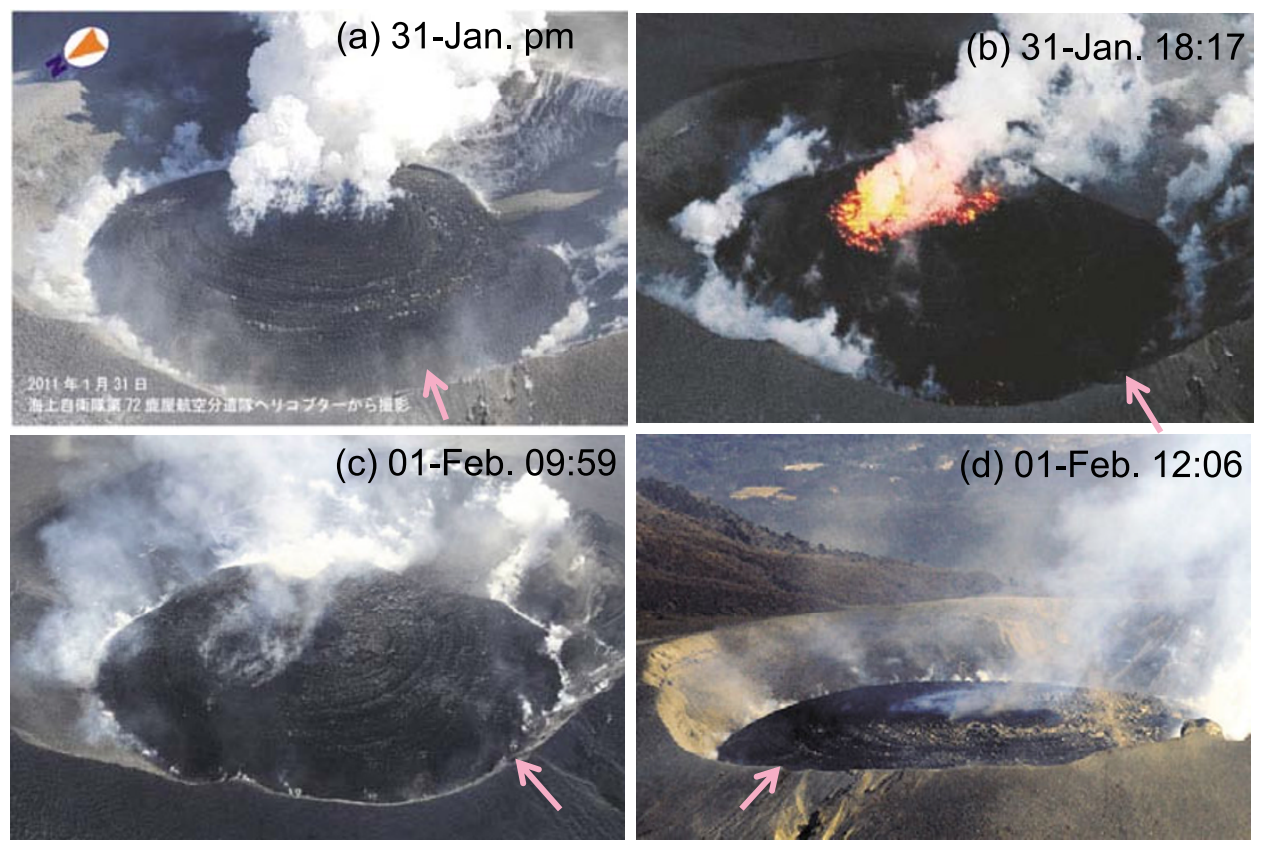

Fig. 6. Aerial photos of the lava cake provided by Japan Meteorology Agency (a), The Yomiuri Shimbun (b), (c), and Asia Air Survey Co. Ltd. (d). These photos show that the lava surface was flattened between January 31 (b) and February 1 (c). The arrows indicate the direction of the view from the camera (Cam.) in Fig. 1.

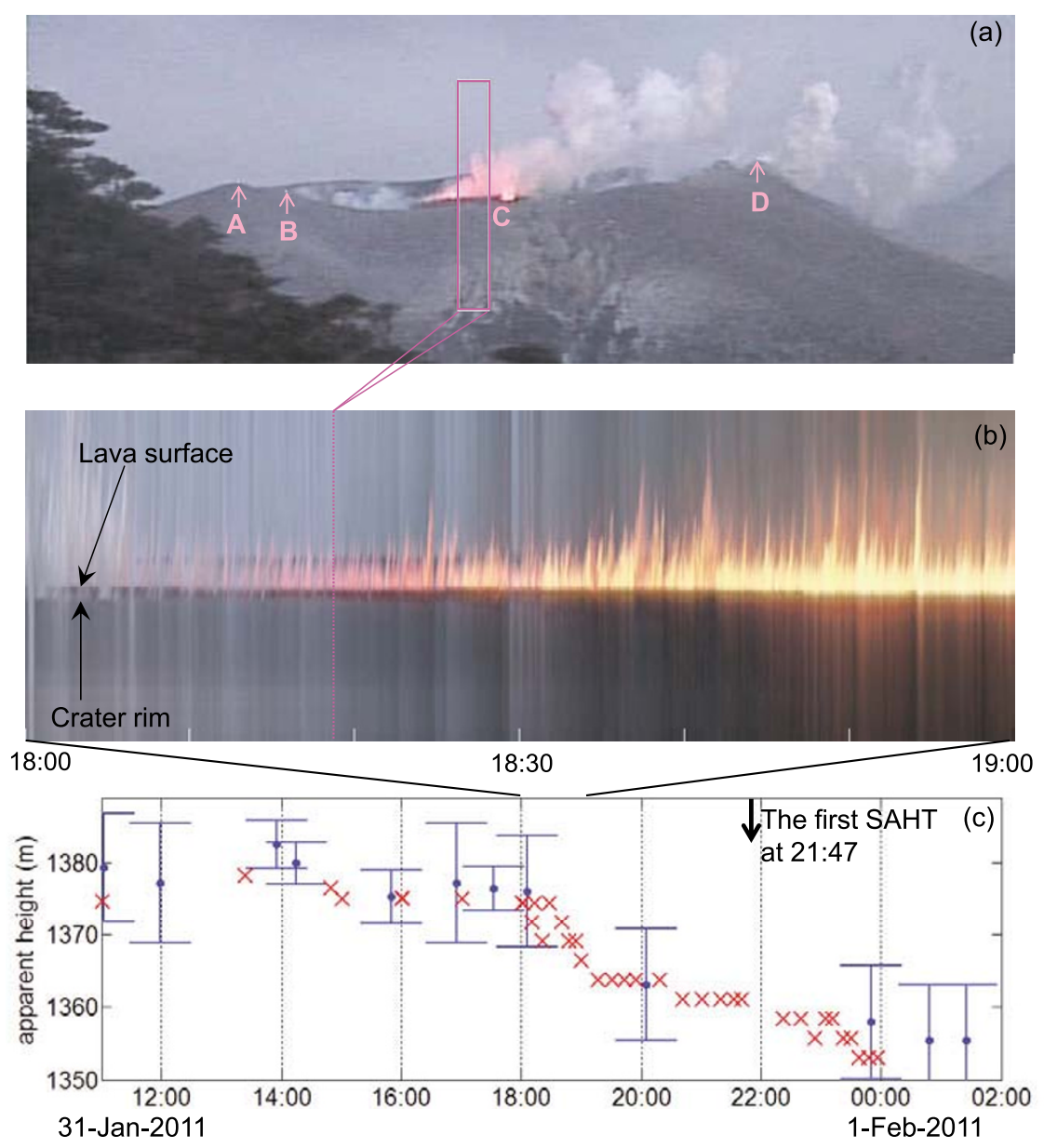

Fig. 7. (a) An image from the monitoring camera (Cam. in Fig. 1) at 18:19 on January 31st, 2011. A-D are the reference points with A-D being $753 \mathrm{~m}$. (b) The colors in the frame $(20 \times 150$ pixels) at $\mathrm{C}$ in (a) are displayed from 18:00 to 19:00 on January 31st. (c) The change of the heights of the lava surface. The red crosses were picked from images like (b) and converted to meters using the scales measured in (a), which are comparable with individual measurements on the selected images (blue circles). 
6) The fundamental frequency was variable both in SHT and SAHT, and there were no systematic difference in the frequency between SHT and SAHT.

We propose a laboratory model shown in Fig. 9(a) as the mechanism that generates the above features. The characteristics of the model are described in detail in the accompanying paper (Lyons et al., 2013). Here we briefly present the relevant points as they apply to the observation at Shinmoe-dake. The model is a gas-flow driven HT generator placed beneath a visco-elastic fluid. The HT generator consists of a pressure controlled valve (a flapping membrane) and a resonator that stabilizes regular oscillation of the valve. The resonator needs to have a low resonant frequency, in order for the resonator to effectively couple with the oscillation of the membrane. Therefore a chamber with a very small elasticity (a balloon) is used in the system. We do not have enough data to specifically identify what is the valve or what is the resonator. Matsumoto et al. (2013) made a seismic array analysis for the seismic signal of the longest SAHT event shown in Fig. 4(b), and located the source at the bottom of the crater. They also suggested the source sometimes shifted deeper into the conduit. Here we only consider it important that the oscillator was located beneath the lava cake and was driven by gas flow not by magma flow. The visco-elastic fluid plays an important role in generating the switching and it represents the pancake dome in the crater. The pressure perturbation measured in the tube beneath the fluid (PS1 and PS2) is regarded to be the seismic source and that measured in the atmosphere (MC1 and MC2) is regarded to be the acoustic wave.

In the laboratory, we observed transitions between bubbling (9(c)) and an open conduit (9(d)), which is a feature of gas transport through such visco-elastic shear-thinning fluid with appropriate combinations of viscosity and gas flux (Divoux et al., 2009, 2011). In the bubbling regime, only pressure sensors beneath the fluid detect pressure perturbations generated by the valve, while acoustic waves in the air are impulsive. The regularity of the valve oscillation is disturbed by pressure fluctuations associated with bubble growth and release from the tube $(9(\mathrm{c}))$. HT generated by the valve oscillation is transmitted to the air when a conduit is established through the fluid (9(d)), which only occurred with high fluid viscosity, resulting in clear and more stable harmonics. When we use water instead of the visco-elastic fluid (9(b)), the pressure fluctuation generated by bubbles is too large to establish regular oscillation of the valve and no HT is generated.

These observations are similar to the Shinmoe-dake HT events. At the beginning of lava effusion, viscosity was too low and deformation of the lava flow at the crater floor was too large to establish HT, as in Fig. 9(b). SHT started at the late stage of the lava effusion, and during the period of SHT degassing continued through the vents near the center of the pancake dome (Fig. 6(a), (b)). The vent (the open circle in Fig. 1(b)) was almost directly above the initial source of lava effusion (the open star in Fig. 1(b)), and a low-viscosity pathway might have been formed from the source to the vents, through which gas escaped preferentially, along with magma that fed the lava dome. Because the temperature along the pathway was kept high and the viscosity low, a stable open conduit was not formed and we consider the gas transport mechanism to have been bubble-dominated. This gas transport mechanism is similar to the bubbling regime in non-newtonian shear-thinning fluid (Fig. 9(c)). After effusion stopped, the degassing rate decreased and the vent was closed (Fig. 6(c), (d)). However, slow degassing continued and pressure accumulated in the lava, and progressive degassing and crystallization of the lava may have also increased its effective viscosity. When the overpressure in the lava became too high, gas was released by a vulcanian explosion and generated an open channel. The increased viscosity of the magma allowed the channel to remain open long enough to permit focused degassing through the channel and the transmission of HT into the atmosphere, as in Fig. 9(d).

\subsection{Comparison with other cases}

Reports of SAHT without SHT are found at many volcanoes (e.g., Karymsky (Johnson and Lees, 2000; Lees et al., 2004), Sangay (Johnson and Lees, 2000), and Santiaguito (Johnson et al., 2009)). Monotonic infrasonic tremor has also been reported both with and without associated seismic tremor (e.g., Kilauea (Fee et al., 2010), Villarrica (Goto and Johnson, 2011; Ripepe et al., 2010), and Sakurajima (Sakai et al., 1996; Yokoo et al., 2008)). However, the switching between SHT and SAHT has only been reported at Reventador volcano, Ecuador (Lees et al., 2008), Arenal volcano, Costa Rica (Hagerty et al., 2000), and Fuego volcano, Guatemala (Lyons et al., 2013). This may be partly due to limited observations because infrasound observations at volcanoes were rare compared with seismic observations until recently. There may also be a bias in reporting. Because observations of AHT with SHT were new and impressive, SAHT was reported in published papers, while the absence of AHT during SHT was not always mentioned explicitly. Even with the reported cases of the switching, the information is limited because the observations were made at remote volcanoes with temporary campaigns that may have captured only parts of eruption sequences. However, all the reported cases share the following common features with the Shinmoe-dake case, which support our model.

1) It occurs in eruptions with mixed explosive and effusive behavior.

2) SHT tends to be associated more frequently with strombolian activity, while SAHT is more often associated with vulcanian activity.

3) All the volcanoes erupted relatively low viscosity magma of basaltic-andesite to low-silica andesite during the events.

An absolute classification between strombolian and vulcanian activity has not been established, and varying terminology has been adopted to describe activity of different volcanoes or even of the same volcano (Marchetti et al., 2009). Here in feature (2) above, 'strombolian' and 'vulcanian' activity indicate a period with small frequent explosions and that with stronger explosions at longer intervals, respectively. 


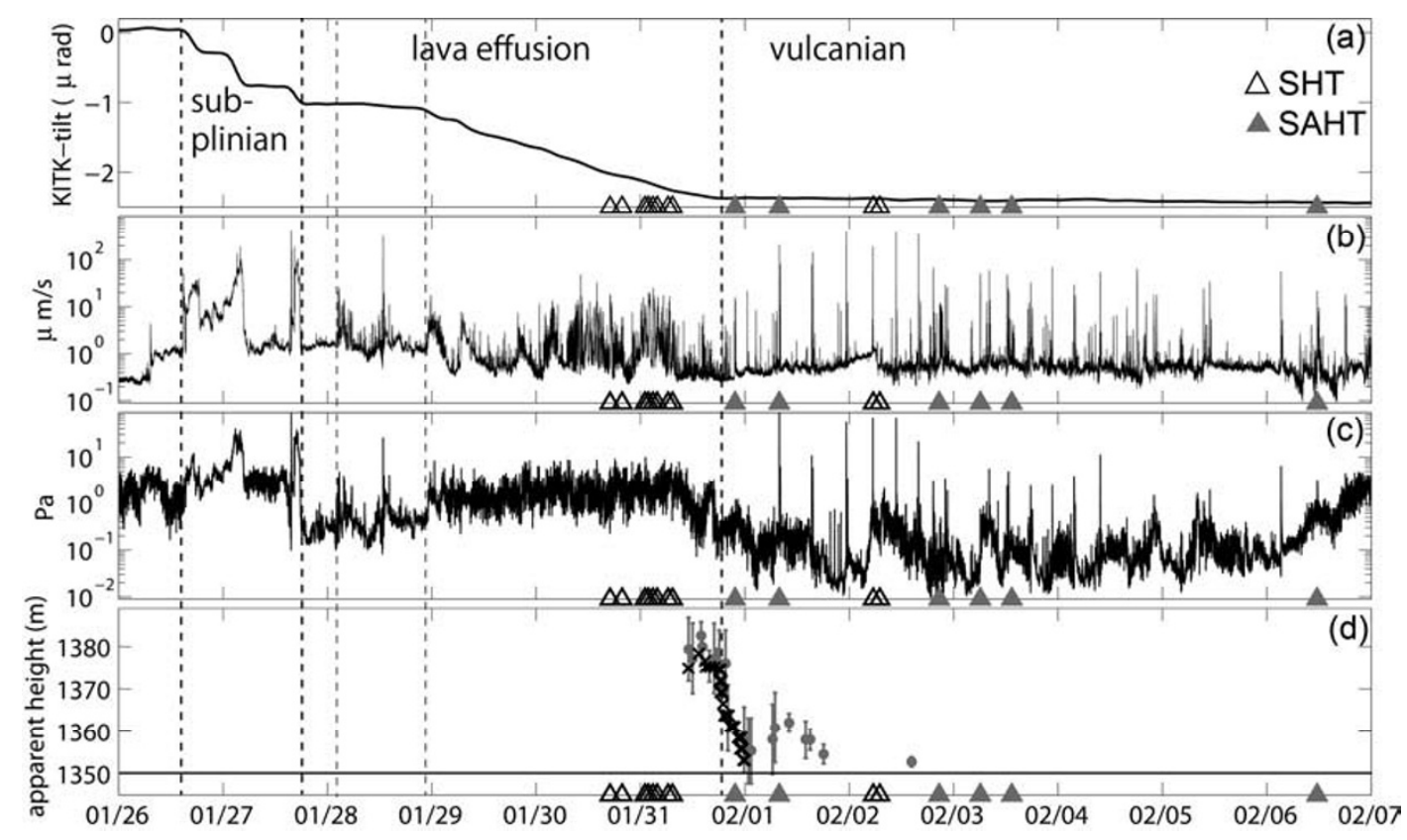

Fig. 8. The time correlation between SHT-SAHT switching and other observations. Open triangles show the time windows in which SHT events are recognized, and solid triangles show SAHT events. The switching occurred during the night of January 31 st and corresponds with the inferred end of magma discharge from the main magma chamber, illustrated by the change in the east-west component of tilt at KITK (a), changes in the intermittency of the pulses in seismic (b) and acoustic (c) signals from frequent small explosions to less-frequent strong explosions, and rapid decrease in the height of the lava surface (d) all coincide with the SHT-SAHT switching. The vertical broken lines indicate changes of the eruptive activity. The timing of the onset of lava effusion is not known. The thin broken lines mark changes of the features of the signals. The black line in (d) at $1350 \mathrm{~m}$ indicates the limit of the visibility inside the crater.

Below we overview the few reported cases of SHT-SAHT switching from the point of view of the above commonality. Although it is somewhat speculative, the aim of this section is to draw attention to the switching phenomena and increase reported cases. Then, the present hypothesis can be tested.

3.2.1 Arenal volcano, April-May, 1997 Arenal has been regularly active since the strong 1968 eruption that opened 3 new craters in 200-m intervals on the west flank of the volcano. The activity in the period of 1984-1998 was characterized by mixed strombolian and effusive eruptions from the highest crater, which is about $200 \mathrm{~m}$ from the summit (Alvarado and Soto, 2002; Wadge et al., 2006). Although the discharged magma is basaltic andesite and sometimes forms a lava pool in the crater, its viscosity is sometimes large enough to allow the generation of pyroclastic flows (Alvarado and Soto, 2002).

Hagerty et al. (2000) were the first to report SHT-SAHT switching. They had seismometers and microphones $2 \mathrm{~km}$ from the summit crater of Arenal volcano during AprilMay, 1997. Several episodes of HT were recorded during the experiment, some of which were recognized to be SAHT. Only one SAHT example ( $\sim 25$ minutes on 7:30 on April 27, 1997) is reported in the paper, and has the following characteristics (Hagerty et al., 2000). Two small explosions occurred, one at about $8 \mathrm{~min}$ before the onset of SAHT and the other $45 \mathrm{~min}$ after the first explosion. The infrasound amplitudes at $2 \mathrm{~km}$ were a few $\mathrm{Pa}$ for the explosions and less than $0.5 \mathrm{~Pa}$ for the tremor. For two hours starting at $\sim 4: 00$, or about 3 hours before the SAHT event, small regularly repeating explosions were recorded by both the seismometers and the microphones for nearly two hours. Their amplitudes were less than $1 \mathrm{~Pa}$, and the time between two successive explosions varies between $0.7-15 \mathrm{~s}$ throughout this period. In the sense that this SAHT event occurred with the transition from frequent explosions (intervals $0.7-$ $15 \mathrm{~s}$ ) to less frequent explosions (an interval of $45 \mathrm{~min}$ ), it is similar to the Shinmoe-dake case. However, lack of information on the features of infrasound signal during SHT or temporal distribution of SHT and SAHT prevents further comparison here.

3.2.2 Reventador volcano, August-September, 2005 Reventador is one of the most active volcanoes in Ecuador. The paroxysmal eruption of November 3, 2002 was very similar to the Shinmoe-dake 2011 eruption. It started with subplinian activity (VEI 4 with andesitic pyroclastic falls and flows) with limited seismic precursory signals. The activity shifted between the 6th and 21 st of November to an effusive stage characterized by the emission of two lava flows (andesite to low-silica andesite) (Ridolfi et al., 2008). Following the spring 2005 lava flows, strombolian activity was first observed from the crater in June 2005.

Lees et al. (2008) performed seismic and acoustic observations for Reventador volcano at $2-8 \mathrm{~km}$ from the vent during August 2 to September 13, 2005. Activity varied considerably over the duration of the six-week seismic deployment. Fluctuations in volcanic activity were reflected in the seismicity, which was relatively mild at the onset of their installation period. Starting on the next day, however, explosion levels picked up and several episodes of high explosivity were observed (Lees et al., 2008). Over the course of the observations, several sequences of SHT or quasi- 


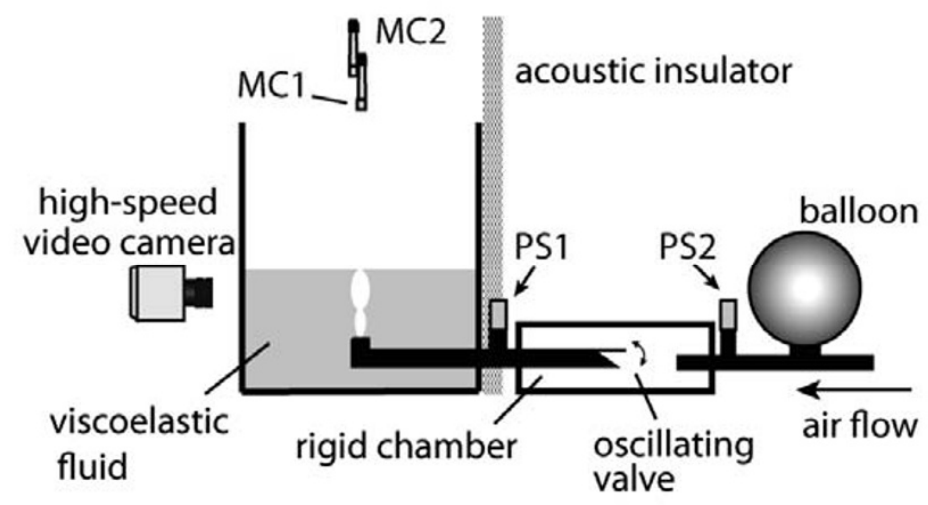

(a)
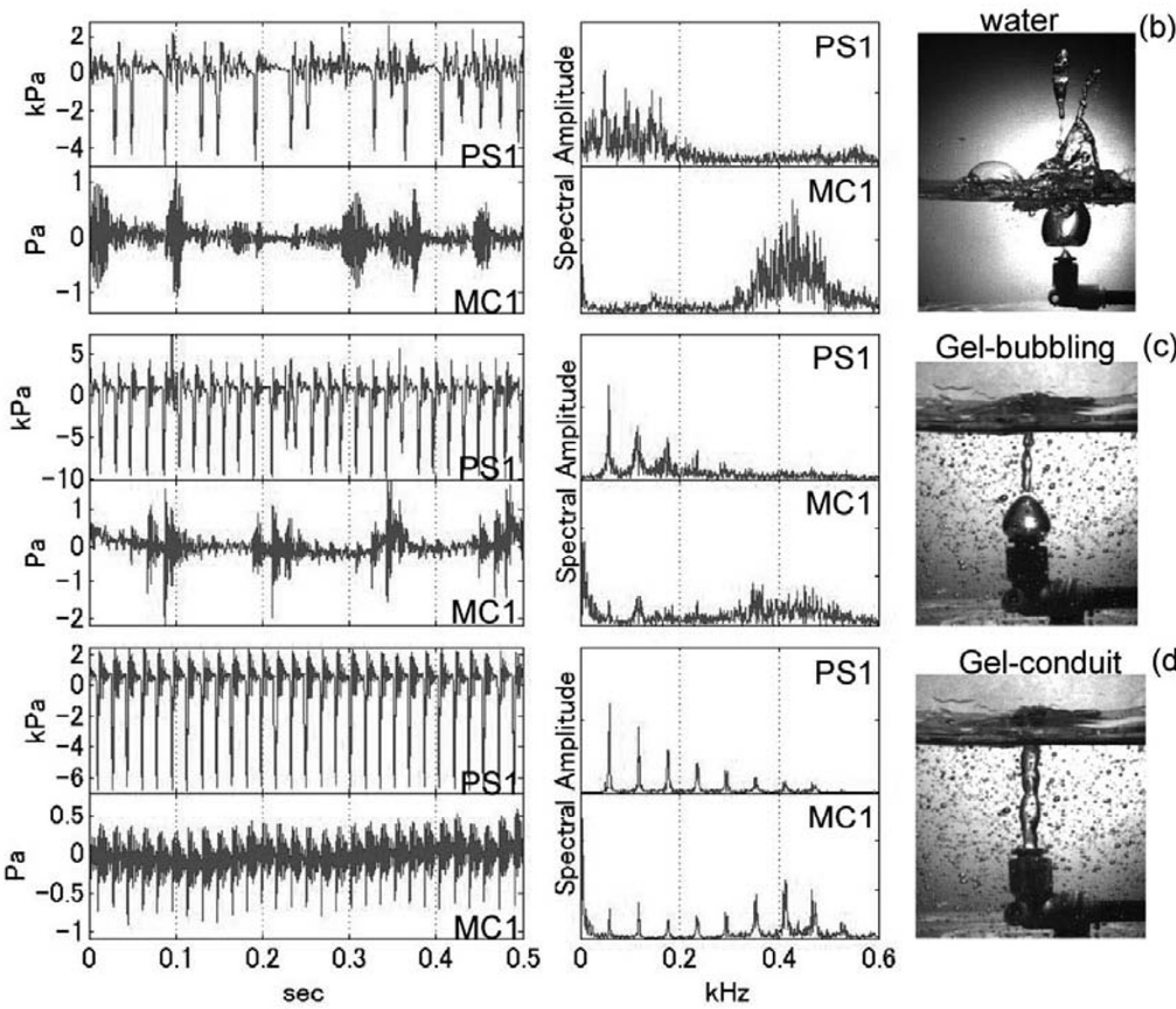

Gel-conduit (d)

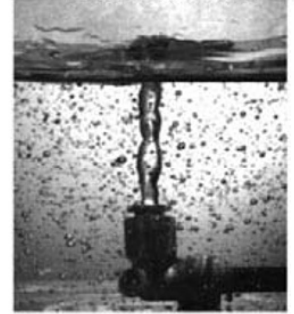

Fig. 9. The laboratory model for SHT-SAHT switching (Lyons et al., 2013). (a) Schematic of the apparatus consisting of a gas-flow driven oscillator beneath a fluid. Pressure sensors (PS1 and PS2) measure pressure in the tube beneath the fluid, while microphones above the fluid (MC1 and MC2) measure the acoustic signal transmitted to the air. Waveforms and spectra for PS1 and MC1 signals and high-speed video images are shown for the cases of water (a), the bubbling (b) and the open-conduit (c) gas transport in a shear-thinning fluid (a hair-gel solution).

periodic tremor were recorded. The harmonic modes were not stable and occasionally lasted for only $30 \mathrm{~s}$. However, significant temporal variations in frequency content were not observed even when amplitudes fluctuated considerably. There was also not a strong correlation between seismic and acoustic signals in these episodes. SAHT events were observed during periods of chugging, which is observed at various volcanoes such as Arenal, Costa Rica (Benoit and McNutt, 1997), Karymsky, Russia (Lees et al., 2004), Sangay (Johnson and Lees, 2000) and Tungurahua (Ruiz et al., 2006), Ecuador, but SHT-SAHT switching have not been reported at Karymsky, Sangay and Tungurahua. The chug- ging sequence is characterized by regularly repeating pulses in both seismic and acoustic signals starting after an explosion with a certain time delay. No clear transition separating periods of SHT and SAHT was reported in the case of Reventador, and all of explosions, SHT, and SAHT could be observed on the same day (Lees et al., 2008).

3.2.3 Fuego volcano, 2008-2009 Fuego volcano is one of the most active volcanoes in Central America and erupts basaltic andesite, sometimes producing subplinian columns and pyroclastic flows that affect the local population (Rose et al., 1978; Lyons et al., 2010). Fuego has been continuously active since the onset of the preset period 
of activity which began with a VEI 2 eruption on May 21, 1999. Despite limited observations, HT has been frequently observed during temporary campaigns (Lyons et al., 2010, 2013). Lyons et al. (2013) observed SHT during a period of strombolian activity in June 2008 that include the effusion of short lava flows, while the following year SAHT was recorded during a period of mild vulcanian activity without associated lava effusion. In this case, the SHT-SAHT switching was associated with subtle changes in magma production rate, which led to a switch from strombolian to vulcanian activity. Lyons et al. (2013) propose that a lower magma production rate in 2009 led to degassing crystallization and an increase in the magma viscosity, thereby allowing the production of open degassing channels in the uppermost portion of the magma column and transmission of HT into the atmosphere.

\section{Conclusion}

Switching from SHT to SAHT was observed during the Shinmoe-dake 2011 eruption. Although similar phenomena have been observed at several volcanoes, the sequence was for the first time correlated with the growth and shrinkage of the lava in the crater and compared with the entire sequence of the eruption activity. SHT-SAHT switching has been generated in the laboratory with gas flow through a feedback oscillator and a visco-elastic fluid (Lyons et al., 2013). The model results show that SAHT was only generated in visco-elastic fluid with sufficiently high viscosity. We propose that the SHT-SAHT switching sequence at Shinmoe-dake may be associated with gradually solidifying lava in the crater. Initially the viscosity was too low and the movement of the lava was too dynamic to establish HT. At the last stage of the lava effusion, HT occurred only in the conduit with impulsive waves in the air, reflecting bubbleregime degassing. After the effusion stopped, the viscosity of the lava accumulated in the crater became high enough to sustain open degassing channels. The cessation of lava discharge and subsequent degassing of the lava dome may have caused the flattening of the lava. SHT-SAHT switching has been observed at other volcanoes erupting magma with similar compositions, and in mixed activity consisting of effusive, strombolian, and vulcanian styles. SHT-SAHT switching may be a good indicator of changes in the conditions of magma rheology and discharge rates of magma and gas.

Acknowledgments. We are grateful to the Yomiuri Shimbun, Asia Air Survey Co. Ltd., and Japan Meteorology Agency for providing the aerial photos of the Shinmoe-dake crater, and Aira-Isa Regional Development Bureau of Kagoshima prefecture for providing video images. Information to estimate the properties of the lava was provided by Y. Suzuki. We also thank M. Takeo, J. M. Lees, and V. Vidal for useful discussions. The manuscript has been significantly improved by constructive comments by the two reviewers (J. B. Johson and T. Nishimura) and the editor (S. R. McNutt). This study has been supported by the MEX Grantin-Aid for Scientific Research (22540431, 21200052), and JSPS Fellowship Summer Program (SP11-039).

\section{References}

Alvarado, G. E. and G. J. Soto, Pyroclastic flow generated by crater-wall collapse and outpouring of the lava pool of Arenal Volcano, Costa Rica,
Bull. Volcanol., 63, 557-568, 2002.

Benoit, J. P. and S. R. McNutt, New constraints on source processes of volcanic tremor at Arenal Volcano, Costa Rica, using broadband seismic data, Geophys. Res. Lett., 24, 449-452, 1997.

Divoux, T., E. Bertin, V. Vidal, and J.-C. Géminard, Intermittent outgassing through a non-Newtonian fluid, Phys. Rev. E, 79, 056204, doi:10.1103/PhysRevE.79.056204, 2009.

Divoux, T., V. Vidal, M. Ripepe, and J.-C. Géminard, Influence of NonNewtonian Rheology on Magma Degassing, Geophys. Res. Lett., 38, L12301, doi:10.1029/2011g1047789, 2011.

Fee, D., M. Garces, M. Patrick, B. Chouet, P. Dawson, and D. Swanson, Infrasonic Harmonic Tremor and Degassing Bursts from Halema'uma'u Crater, Kilauea Volcano, Hawaii, J. Geophys. Res., 115, B11316, doi:10.1029/2010jb007642, 2010.

Fink, J. H. and R. W. Griffiths, Morphologye, ruptionrates, andrheologyo f lava domes: Insights from laboratory models, J. Geophys. Res., 103 527-545, 1998.

Giordano, D., J. K. Russell, and D. B. Dingwell, Viscosity of magmatic liquids: A model, Earth Planet. Sci. Lett., 271, 123-134, 2008.

Goto, A. and J. B. Johnson, Monotonic Infrasound and Helmholtz Resonance at Volcan Villarrica (Chile), Geophys. Res. Lett., 38, L06301, doi:10.1029/2011 gl046858, 2011.

Hagerty, M. T., S. Y. Schwartz, M. A. Garces, and M. Protti, Analysis of seismic and acoustic observations at Arenal Volcano, Costa Rica, 19951997, J. Volcanol. Geotherm. Res., 101, 27-65, 2000.

Imura, R. and T. Kobayashi, Eruptions of Shinmoedake Volcano, Kirishima Volcano Group, in the last 300 years, Bull. Volcanol. Soc. Jpn., 36, 135-148, 1991 (in Japanese with English abstract).

Johnson, J. B. and J. M. Lees, Plugs and chugs-seismic and acoustic observations of degassing explosions at Karymsky, Russia and Sangay, Ecuador, J. Volcanol. Geotherm. Res., 101, 67-82, 2000.

Johnson, J. B., R. Sanderson, J. Lyons, R. Escobar-Wolf, G. Waite, and J. M. Lees, Dissection of a composite volcanic earthquake at Santiaguito, Guatemala, Geophys. Res. Lett., 36, doi:10.1029/2009gl039370, 2009.

Julian, B. R., Volcanic Tremor-Nonlinear excitation by fluid-flow, J. Geophys. Res., 99, 11,859-11,877, 1994.

Kozono, T., H. Ueda, T. Ozawa, T. Koyaguchi, E. Fujita, A. Tomiya, and Y. J. Suzuki, Magma discharge variations during the 2011 eruptions of Shinmoe-dake volcano, Japan, revealed by geodetic and satellite observations, Bull. Volcanol., 75, doi:10.1007/s00445-013-0695-4, 2013.

Lees, J. M., E. I. Gordeev, and M. Ripepe, Explosions and periodic tremor at Karymsky volcano, Kamchatka, Russia, Geophys. J. Int., 158, 1151$1167,2004$.

Lees, J. M., J. B. Johnson, M. Ruiz, L. Troncoso, and M. Welsh, Reventador Volcano 2005: Eruptive activity inferred from seismo-acoustic observation, J. Volcanol. Geotherm. Res., 176, 179-190, 2008.

Lejeune, A. M. and P. Richet, Rheology of crystal-bearing silicate melts: An experimental study at high viscosities, J. Geophys. Res., 100, 42154229, 1995.

Lesage, P., M. M. Mora, G. E. Alvarado, J. Pacheco, and J.-P. Metaxian, Complex behavior and source model of the tremor at Arenal volcano, Costa Rica, J. Volcanol. Geotherm. Res., 157, 49-59, 2006.

Lyons, J. J., G. P. Waite, W. I. Rose, and G. Chigna, Patterns in open vent, strombolian behavior at Fuego volcano, Guatemala, 2005-2007, Bull. Volcanol., 72, 1-15, 2010.

Lyons, J. J., M. Ichihara, A. Kurokawa, and J. M. Lees, Switching between seismic and seismo-acoustic harmonic tremor simulated in the laboratory: Insights into the role of open degassing channels and magma viscosity, J. Geophys. Res., 2013.

Marsh, B. D., On the crystallinity, probability of occurrence, and rheology of lava and magma, Contrib. Mineral. Petrol., 78, 85-98, 1981.

Marchett, E., M. Ripepe, A. J. L. Harris, and D. Delle Donne, Tracing the differences between Vulcanian and Strombolian explosions usinginfrasonic and thermal radiation energy, Earth Planet. Sci. Lett., 279, 273-281, 2009.

Matsumoto, S., H. Shimizu, T. Matsushima, K. Uehira, Y. Yamashita, M. Nakamoto, M. Miyazaki, and H. Chikura, Short-term spatial change in a volcanic tremor source during the 2011 Kirishima eruption, Earth Planets Space, 65, 323-329, 2013.

Miyagi, I. and Y. Maejima, Estimation of eruptive temperatures based on the color data of digital cameras, Bull. Volcanol. Soc. Jpn., 57, 45-50, 2012 (in Japanese with English abstract).

Moore, G., Interpreting $\mathrm{H}_{2} \mathrm{O}$ and $\mathrm{CO}_{2}$ contents in melt inclusions: Constraints from solubility experiments and modeling, Rev. Mineral. Geochem., 69, 333-362, 2008.

Nakada, S., M. Nagai, T. Kaneko, Y. Suzuki, and F. Maeno, The outline of 
the 2011 eruption at Shinmoe-dake (Kirishima), Japan, Earth Planets Space, 65, this issue, 475-488, doi:10.5047/eps.2013.03.016, 2013.

Nakao, S., Y. Morita, H. Yakiwara, J. Oikawa, H. Ueda, H. Takahashi, Y. Ohta, T. Matsushima, and M. Iguchi, Volume change of the magma reservoir relating to the 2011 Kirishima Shinmoe-dake eruption-Charging, discharging and recharging process inferred from GPS measurements, Earth Planets Space, 65, this issue, 505-515, doi:10.5047/eps.2013.05.017, 2013.

Ridolfi, F., M. Puerini, A. Renzulli, M. Menna, and T. Toulkeridis, The magmatic feeding system of El Reventador volcano (Sub-Andean zone, Ecuador) constrained by texture, mineralogy and thermobarometry of the 2002 erupted products, J. Volcanol. Geotherm. Res., 176, 94-106, 2008.

Ripepe, M., E. Marchetti, C. Bonadonna, A. J. L. Harris, L. Pioli, and G. Ulivieri, Monochromatic infrasonic tremor driven by persistent degassing and convection at Villarrica Volcano, Chile, Geophys. Res. Lett., 37, L15303, doi:10.1029/2010g1043516, 2010.

Rose, W. I., A. T. Anderson, L. G. Woodruff, and S. B. Bonis, The October 1974 basaltic tephra from Fuego volcano: Description and history of the magma body, J. Volcanol. Geotherm. Res., 4, 3-53, 1978.

Ruiz, M., J. M. Lees, and J. B. Johnson, Source constraints of Tungurahua volcano explosion events, Bull. Volcanol., 68, 480-490, 2006.

Rust, A. C., N. J. Balmforth, and S. Mandre, The feasibility of generating low-frequency volcano seismicity by flow through a deformable channel, in Fluid Motions in Volcanic Conduits, edited by S. J. Lane and J. S. Gilbert, pp. 45-56, Geol. Soc., London, 2008.

Sakai, T., H. Yamasato, and K. Uhira, Infrasound accompanying C-type tremor at Sakurajima Volcano, Bull. Volcanol. Soc. Jpn., 41, 181-185, 1996 (in Japanese with English abstract).

Suzuki, Y., A. Yasuda, N. Hokanishi, T. Kaneko, S. Nakada, and T. Fujii, Syneruptive deep magma transfer and shallow magma remobilization during the 2011 eruption of Shinmoe-dake, Japan-Constraints from melt inclusions and phase equilibria experiments-, J. Volcanol. Geotherm. Res., 257, 184-204, 2013.

Tsutsui, M., K. Tomita, and T. Kobayashi, Fumarolic activity since December 2003 and volcanic activity during the Meiji and Taisho eras (18801923) of Ohachi Volcano, Kishirima Volcano Group, Southern Kyushu, Japan, Bull. Volcanol. Soc. Jpn., 50, 475-489, 2005 (in Japanese with English abstract).

Ueda, H., T. Kozono, E. Fujita, Y. Kohno, M. Nagai, Y. Miyagi, and T. Tanada, Crustal deformation associated with the 2011 Shinmoe-dake eruption as observed by tiltmeters and GPS, Earth Planets Space, 65, this issue, 517-525, doi:10.5047/eps.2013.03.001, 2013.

Wadge, G., Dorta, D. Oramas, and P. D. Cole, The magma budget of VolcanArenal, Costa Rica from 1980 to 2004, J. Volcanol. Geotherm. Res., 157, 60-74, 2006.

Yokoo, A., T. Tameguri, M. Iguchi, and K. Ishihara, Sequence and characteristics of the 2007 eruption at Showa Crater of Sakurajima Volcano, Ann. Disas. Prev. Res. Inst., Kyoto Univ., 51B, 267-273, 2008 (in Japanese with English Abstract).

M. Ichihara (e-mail: ichihara@eri.u-tokyo.ac.jp), J. J. Lyons, and A. Yokoo 